\title{
Nueva regulación para la protección de menores y personas vulnerables en el Estado de la Ciudad del Vaticano
}

Gerardo NúÑEZ

Profesor Adjunto de Derecho Procesal Canónico

Universidad de Navarra. Facultad de Derecho Canónico. Pamplona

orcid 0000-0003-3417-3033

gnunez@unav.es

SUMARIO: 1. Algunos aspectos procesales particulares. 2. Obligación de denunciar y la incidencia del secreto en el Derecho Canónico. 2.1. Concepto de denuncia. 2.2. Victima del abuso y su obligación de denunciar. 2.3. Obligación de conservar o revelar un secreto por parte de terceras personas. 3. Medidas a favor de la protección y acompañamiento del menor. 3.1. Medidas legales en la protección de los menores. 3.2. Actuaciones sociales en favor del menor: acompañamiento y escucha, y asistencia espiritual, médica y social de las víctimas. 4. Servicio responsable en las acciones que se han de implementar para la protección de menores. 4.1. El servicio de acompañamiento para las víctimas de abuso. El Supervisor. 4.2. Competencias: selección, contratación, idoneidad y formación del personal. 5. Algunas experiencias para tener en cuenta en la labor pastoral con menores. 5.1. Relaciones interpersonales con el menor. 5.2. Estructuras y lugares para compartir en las actividades pastorales. 6. Consideraciones finales.

La crisis de los abusos sexuales a menores ha llevado a la Iglesia no solo a la purificación personal, a una acción pastoral más cercana con las víctimas de estas execrables acciones, sino también a una actuación jurídica más contundente con aquellos clérigos y religiosos culpables de la comisión de esos 
delitos ${ }^{1}$. Esta crisis también ha llevado a una mayor reflexión y concienciación a propósito de la protección de menores y personas vulnerables, considerando que es una parte integral del mensaje del evangelio que la Iglesia y todos sus miembros están llamados a difundir en el mundo. Esta acción se ha materializado en una Pontificia Comisión para la tutela de menores, creada el 22 de marzo del $2014^{2}$, con el fin de ofrecer al Romano Pontífice propuestas e iniciativas -praxis virtuosas y programas de educación, formación e instrucción- orientadas a mejorar las normas y los procedimientos para la protección de los menores y adultos vulnerables. Durante estos años la Comisión ha sido un instrumento de gran ayuda para animar y promover el compromiso de toda la Iglesia, y dar respuestas de justicia y misericordia.

En febrero del 2015, el Santo Padre Francisco resaltaba el trabajo que realizaba esta Comisión Pontificia, enviando una carta a los Presidentes de las Conferencias Episcopales y a los Superiores de los Institutos de Vida Consagrada y las Sociedades de vida Apostólica ${ }^{3}$. En dicha carta ya se preanunciaban bastantes de las medidas y actuaciones que ahora se empiezan a promulgar en normas. Así podemos resaltar que «las familias deben saber que la Iglesia no escatima esfuerzo alguno para proteger a sus hijos, y tienen el derecho de dirigirse a ella con plena confianza», y que la Iglesia actuará con contundencia ya que «no hay absolutamente lugar en el ministerio para los que abusan de los menores». En este sentido, «corresponde al Obispo diocesano y a los $\mathrm{Su}-$ periores mayores la tarea de verificar que en las parroquias y en otras instituciones de la Iglesia se garantice la seguridad de los menores y los adultos vulnerables». Además, se deberán «establecer programas de atención pastoral, que podrán contar con la aportación de servicios psicológicos y espirituales» que atiendan a las víctimas, siendo responsabilidad de los Pastores y de los que están al frente de las comunidades religiosas de ello, así como que han de es-

${ }^{1}$ Cfr. Juan Pablo II, Motu proprio Sacramentorum sanctitatis tutela, 30-IV-2001, AAS 93 (2001) 737-739; BENEDICTO XVI, Motu proprio Normae de gravioribus delictis, 21-V-2010, AAS 102 (2010) 419-434.

2 Quirógrafo de Su Santidad Papa Francisco para la creación de la Pontificia Comisión para la tutela de los menores, 22-III-2014, http://bit.ly/2DHMw6A; su Estatuto puede verse en http:// bit.ly/2JavykU.

3 «La tarea que le he encomendado incluye la asistencia a vosotros y a vuestras Conferencias, mediante un intercambio mutuo de "praxis virtuosas" y de programas de educación, formación e instrucción por lo que se refiere a la respuesta que se ha de dar a los abusos sexuales»: Carta del Santo Padre Francisco a los Presidentes de las Conferencias Episcopales y a los Superiores de los Institutos de Vida Consagrada y las Sociedades de vida Apostólica acerca de la Comisión Pontificia para la tutela de menores, 2-II-2015, http://bit.ly/2IWvwha. 
tar «disponibles para el encuentro con los que han sufrido abusos y sus seres queridos: se trata de valiosas ocasiones para escuchar y pedir perdón a los que han sufrido mucho».

Fruto del trabajo de esta Comisión Pontificia, y del encuentro de los Presidentes de las Conferencias Episcopales del 21-24 de febrero pasado sobre los abusos sexuales a menores de edad, el Santo Padre anunciaba en su discurso final de la reunión una serie de medidas que se deberán desarrollar en diversos campos: 1. La protección de los menores: el objetivo principal de cualquier medida es el de proteger a los menores e impedir que sean víctimas de cualquier abuso psicológico y físico. 2. Seriedad impecable: la Iglesia no se cansará de hacer todo lo necesario para llevar ante la justicia a cualquiera que haya cometido tales crímenes. 3. Una verdadera purificación: empeño hacia la santidad en los pastores. 4. La formación: la exigencia de la selección y de la formación de los candidatos al sacerdocio. 5. Reforzar y verificar las directrices de las Conferencias Episcopales. 6. Acompañar a las personas abusadas. 7. Mundo digital: la protección de los menores debe tener en cuenta las nuevas formas de abuso sexual $\mathrm{y}$ de abusos de todo tipo que los amenazan en los ambientes en donde viven y a través de los nuevos instrumentos que usan. 8. El turismo sexual ${ }^{4}$.

La primera medida adoptada por la Santa Sede tras esta reunión es la promulgación de tres documentos para el Estado de la Ciudad del Vaticano, el pasado 26 de marzo ${ }^{5}$. Se tratan de dos normas y un documento pastoral. Las normas tratan de delitos de abusos de menores y personas vulnerables (sexto mandamiento, incluida la pornografía) y su aplicación en las sedes extraterritoriales del Vaticano, como las nunciaturas. El tercer documento trata de unas líneas-guías pastorales para la prevención del abuso de menores y la denuncia de eventuales casos: Motu proprio sobre la protección de menores y de las personas vulnerables (a partir de ahora mp sobre la protección de menores) ${ }^{6}$, Ley CCXVII sobre la protección de menores y personas vulnerables del Estado de la Ciudad del Vaticano (a partir de ahora Ley CCXVII) ${ }^{7}$ y el Vademécum para la protección de los menores y personales vulnerables para el Vicariato de la Ciudad

\footnotetext{
${ }^{4}$ Discurso final del Santo Padre Francisco del encuentro "La protección de los menores en la Iglesia", 24-II-2019, http://bit.ly/2Lld1Fk.

${ }^{5}$ La traducción al castellano de estas normas es mía.

${ }^{6} \mathrm{Mp}$ sobre la protección de menores y de las personas vulnerables, 26-III-2019, http://bit.ly/ 2ZQSwDy.

7 Ley CCXVII sobre la protección de menores y personas vulnerables del Estado de la Ciudad del Vaticano, 26-III-2019, http://bit.ly/2WjZE9g.
} 
del Vaticano (a partir de ahora Vademécum) ${ }^{8}$. Con estas tres disposiciones se fortalece el marco institucional y normativo para prevenir y combatir los abusos de menores y las personas vulnerables. Su finalidad es la de «acoger generosamente a los menores y las personas vulnerables y crear un ambiente seguro para ellos».

Nos parece interesante resaltar una última cuestión en esta introducción. Tanto el mp sobre la protección de menores como la Ley CCXVII están dirigidas a un amplio ámbito de aplicación: todas aquellas personas que son vulnerables ya sean menores de edad, como aquellas personas que por su «estado de enfermedad, deficiencia física o mental o privación de la libertad personal es vulnerable y, de hecho, incluso ocasionalmente, limita su capacidad de intención o de querer o, en cualquier caso, de resistir la ofensa» ${ }^{9}$. Sin embargo, el Vademécum está pensado para la protección de abusos en los menores de edad: señalando aquellas medidas que se han de adoptar en estos casos, e indica que «a los efectos de estas directrices, las "personas vulnerables" se equiparan a los "menores de edad"»

En las tres normas se suelen repetir las ideas, incluso con las mismas palabras textuales: en el mp sobre la protección de menores se recalcan los principios; la Ley CCXVII especifica contenidos y ámbito de aplicación; el Vademécum es un conjunto de experiencias para tener en cuenta. El conjunto de estas disposiciones se puede englobar en cuatro grandes apartados: disposiciones procesales en relación a este tipo de procesos; medidas a favor de la protección del menor, pastorales y procesales; oficios responsables en las acciones que se han de implementar para la protección de menores: competencias y actuaciones; experiencias a tener en cuenta en la labor pastoral con menores.

$\mathrm{Al}$ comentar estas normas nos centraremos preferentemente en las actuaciones y medidas que, a nuestro entender, podrían tener una aplicación en ámbito canónico por parte de los Obispos y Conferencias Episcopales. No trataremos de aquellos aspectos que tienen solo su validez en el Estado de la Ciudad del Vaticano: dichos aspectos son relevantes, pero deberían ser objeto de un estudio profundo que excede estas líneas que ahora se adjuntan.

\footnotetext{
${ }^{8}$ Vademécum para la protección de los menores y personales vulnerables, 26-III-2019, http:// bit.ly/2LjpGZh.

${ }^{9}$ Ley CCXVII, art. 1, n. 3.

${ }^{10}$ Vademécum, A.
} 


\section{Algunos aspectos procesales particulares}

Antes de estudiar el aspecto procesal que, según nuestro parecer, incide más en ámbito canónico -la obligación de denunciar-, queremos señalar algunas concreciones procesales que se refieren a la declaración por parte de un menor de edad y algunos mensajes con relación al sacerdote acusado.

Las concreciones procesales para la declaración de menores de edad nos parece que están tomadas de las experiencias de leyes estatales ${ }^{11}$. Nos referimos a las siguientes:

a) En la audiencia, el menor puede estar acompañado por su abogado, así como por un adulto de su confianza admitido por la autoridad de procedimiento; si es menor de 14 años siempre se lleva a cabo con la ayuda de un psicólogo; la declaración se documenta mediante la grabación en video, que sirve como prueba ante el tribunal (cfr. Ley CCXVII, art. 5).

b) En caso de que los representantes legales estén en conflicto de intereses con el menor, el Promotor de justicia solicita al juez que designe un administrador especial que, a expensas del Estado de la Ciudad del Vaticano, represente sus intereses (cfr. Ley CCXVII, art. 6).

c) Para proteger al menor, los procedimientos y procesos se pueden realizar a puerta cerrada; la declaración del menor se puede hacer por videoconferencia (o mediante el uso de un espejo de cristal junto con un sistema de intercomunicación) (cfr. Ley CCXVII, art. 7).

Por otra parte, tanto en el mp sobre la protección de menores como en la Ley CCXVII se insiste en una serie de mensajes con relación al sacerdote acusado. Entre ellos:

a) La realización de un juicio imparcial y justo, y siguiendo el principio de legalidad; presunción de inocencia; preservación de la reputación y buena fama del acusado; informarle con prontitud de la denuncia y que le asista un abogado en su defensa; se hace todo lo posible para rehabilitar la buena reputación de los acusados injustamente de estos de-

${ }^{11}$ Otros aspectos procesales que señala el art. 2 de la Ley CCXVII: estos delitos son perseguibles de oficio; su plazo de prescripción es de veinte años y comienza, en el caso de un delito contra un menor, a partir de la fecha en que cumpla los dieciocho años de edad. 
litos (cfr. mp sobre la protección de menores y Vademécum, F, nn. 11 h) y 12).

b) Si hay condena por abuso, se removerá de su oficio al condenado; si el caso lo requiere, existe la posibilidad de tomar previamente medidas cautelares ${ }^{12}$; debe existir proporcionalidad entre el delito y la sentencia; al acusado se ofrece la posibilidad de apoyo para su rehabilitación psicológica y espiritual, y reintegración social del condenado (cfr. mp sobre la protección de menores, Ley CCXVII, art. 6, Vademécum, F, nn. $11 \mathrm{~g}, 13$ y 15).

Se insiste en la pronta puesta en marcha de la investigación y, si es el caso, el enjuiciamiento de cualquier abuso contra menores o contra personas vulnerables (cfr. mp sobre la protección de menores). En el Vademécum, F, n. 8, se recuerda que se ha de realizar con diligencia la investigación preliminar de acuerdo con el c. 1717 CIC 83. En esta investigación se debe verificar la culpabilidad de la conducta, circunstancias del posible delito, edad de las personas ofendidas, los daños causados y la posible interacción con el foro sacramental. Además, se pueden recopilar todos los documentos, pruebas y testimonios, informes de expertos recogidos en asuntos civiles, así como cualquier juicio o decisión con respecto al tema de la investigación por parte de los órganos jurisdiccionales del Estado (de la Ciudad del Vaticano). Se podrá suspender el procedimiento en espera de la conclusión de la investigación civil (cfr. Vademécum, F, n. 10). Si la investigación revela la probabilidad de un crimen, se traslada el caso al Dicasterio competente. De lo contrario, se cierra con un decreto motivado, manteniendo en su archivo la documentación que certifica las actividades realizadas y los motivos de la decisión tomada ${ }^{13}$ (cfr. Vademécum, F, n. 14).

Podemos encontrar normas paralelas en el Código de Derecho Canónico (como hemos señalado parcialmente) al hablar del desarrollo del proceso penal (cfr. cc. 1717 y ss., así como la consecución de las pruebas). Lo más novedoso de esta normativa es todo lo relacionado con la declaración del menor

12 Actuaciones disciplinares, excluyendo las penas, como alejar al imputado del ministerio sagrado o de un oficio o cargo eclesiásticos, imponerle o prohibirle residir en un determinado lugar o territorio, o también impedirle que participe públicamente en la santísima eucaristía; todas estas medidas se han de revocar si desaparece el motivo que las originó, y cesan por el mismo derecho al concluir el proceso penal (cfr. c. 1722). En estos casos es el Promotor de Justicia quien solicita la adopción de estas medidas: cfr. Ley CCXVII, art. 6.

${ }^{13}$ Cfr. c. 1719 CIC 83. 
(asistencia de psicólogo y abogado, hacerla por videoconferencia, etc.) tanto en la denuncia ante la autoridad competente como en el proceso posible posterior. Estas medidas se podrían adaptar a lo que la legislación civil de cada país prevea para este tipo de situaciones. También parece interesante destacar la insistencia en la observancia de una recta actuación jurídica, con referencias explícitas al principio de legalidad, al derecho de defensa, a la proporcionalidad entre el delito y la sentencia, a la presunción de inocencia, etc.: no nos parece algo superfluo, habida cuenta de la sensibilidad existente en la actualidad, tanto en la sociedad como en el Pueblo de Dios, que podría llevar a decisiones precipitadas o incluso injustas.

\section{ObligACiÓN DE DENUNCIAR Y LA INCIDENCIA DEL SECRETO EN EL DERECHO CANÓNICO}

Después de ver las principales disposiciones en materia procesal, nos vamos a referir a la obligación de denunciar de aquellos que tienen conocimiento de estos delitos. La regulación se mueve en una doble dirección:

a) En cuanto a los funcionarios de la Curia Romana y del Estado de la Ciudad del Vaticano, y su responsabilidad jurídica en el ejercicio de sus cargos oficiales en relación al bien común: se castiga con sanciones administrativas y penales la omisión o el retraso infundado de la denuncia ${ }^{14}$.

b) A los agentes pastorales (en los que también estarían las personas incluidas en el apartado anterior en su labor pastoral): se recalca la obligación moral de defender el bien común eclesial ${ }^{15}$.

No vamos a estudiar la obligación jurídica que señala la Ley para los oficios de la Curia Vaticana o de autoridades policiales del Estado de la Ciudad del Vaticano al no ser, por ahora, un ámbito jurídico extensible a las Iglesias particulares en su organización eclesiástica. Respecto a la obligación moral de denunciar, enfocaremos tres cuestiones: el concepto de denuncia, la obligación de denunciar por parte de la persona abusada y cómo se debe comportar el tercero que conoce un posible caso de abuso de menores.

${ }^{14}$ Cfr. Ley CCXVII, art. 3, nn. 1-2.

${ }^{15}$ Cfr. mp sobre la protección de menores, Ley CCXVII, art. 3, n. 3 y Vademécum, F, n. 3. 


\subsection{Concepto de denuncia}

En sentido amplio, la palabra denuncia significa dar a conocer, comunicar un hecho jurídicamente relevante ${ }^{16}$. El término proviene del latín denuncio, que significa anunciar, declarar. Cualquier persona puede poner en conocimiento de la autoridad eclesiástica unos hechos constitutivos de delito, indicando o no a su autor ${ }^{17}$, pero de suyo no puede dar inicio a un proceso penal, que solo se procederá después de haberse realizado la oportuna investigación previa (cfr. cc. 17171719 CIC) y una vez que el ordinario competente haya decretado el inicio de un proceso penal (cfr. c. $1718 \$ 1,1^{\circ}$ ). En este supuesto, entregará las actas de la investigación al promotor de justicia para que presente al juez el escrito acusatorio (cfr. c. $1721 \$ 1$ y c. $1472 \$ 1)^{18}$, que comporta la formal apertura de un proceso penal, y sostenga la acusación a lo largo del desarrollo del proceso ${ }^{19}$.

Conviene recordar que en la actual regulación penal no se recoge la obligación de denunciar los delitos, como se indicaba en el c. $1935 \$ 2$ CIC $17^{20}$ : solo sigue vigente el derecho de cualquier fiel a denunciar por velar por la justicia, o para reparar algún escándalo u otro mal público o general ${ }^{21}$, o para procurar la reparación de daños causados.

\subsection{Victima del abuso y su obligación de denunciar}

Recordemos que en la anterior legislación del CIC 17 existía obligación jurídica de denunciar en uno de los delitos más graves relacionado con el sa-

${ }^{16}$ Cfr. P. E. Gudenus, «Denuncia», en J. Otaduy - A. Viana - J. Sedano (eds.), Diccionario General de Derecho Canónico [DGDC], III, Cizur Menor 2012, 56-57.

17 Tradicionalmente, en Derecho Canónico no se tenían en cuenta las denuncias anónimas, aunque podían ser ocasión para iniciar una investigación previa si se veía conveniente. Una acusación escrita, firmada por un desconocido pero sin dirección del firmante, debe ser considerada como denuncia anónima, porque no basta para identificar al denunciante: cfr. A. CALABRESE, sub c. 1390, en Comentario Exegético al Código de Derecho Canónico, IV/1, Pamplona 1996, 565.

${ }^{18}$ En Derecho Canónico se excluye la figura de la acusación penal privada o popular. Queda también descartada la querella, que solo podría presentarla la persona lesionada en aquellos delitos para cuya persecución se requiriese precisamente su intervención, como los que atentan contra la buena fama, pudiendo solo ejercitar la acción de resarcimiento de los daños causados por el delito (cfr. cc. 1729-1731).

19 Cfr. J. M. SANCHIS, «Acusación penal», DGDC, I, 191-193.

20 «Existe obligación de denunciar en todos aquellos casos en que esta obligación la imponen alguna ley o precepto peculiar legítimo, o bien el mismo derecho natural por razón de peligro de la fe o de la religión o a causa de algún otro mal público inminente»: c. $1935 \$ 2$ CIC 17.

${ }^{21}$ Es decir, puede darse una obligación por derecho natural, teniendo en cuenta el bien de la Iglesia, o de los fieles afectados por el delito en cuestión. 
cramento de la Penitencia: la solicitación en confesión. Por las circunstancias tan peculiares en las que se consuma el delito de solicitación en confesión, puede suceder que también sea ocasión e inicio de la perpetración del crimen de abuso de menores o de personas vulnerables. Por esto, ya desde 1938, la Congregación del Santo Oficio relacionaba la pederastia con este delito de solicitación en confesión en su tratamiento procesal: su enjuiciamiento debía seguir las normas particulares de la solicitación en confesión y su tramitación se reservaba al Santo Oficio ${ }^{22}$.

El CIC 17 regulaba la solicitación en confesión imponiendo la obligación jurídica de denunciar a todo el que fuese víctima del delito «en el plazo de un mes, ante el Ordinario local o ante la S. Congregación del Santo Oficio, al sacerdote que sea reo del delito de solicitación en la confesión; y el confesor, bajo pena de pecado mortal, debe amonestarle acerca de esta obligación» (c. 904 CIC 17) ${ }^{23}$; y, a su vez, en el c. 2368 se penalizaba la omisión de la denuncia contra el sacerdote solicitante: $\ll \$ 2$ Y el fiel que a sabiendas dejare de denunciar dentro del mes, en contra de lo que prescribe el c. 904, al sacerdote por el cual fue solicitado, incurre en excomunión latae sententiae no reservada a nadie, de la cual solo puede ser absuelto después que haya cumplido su obligación o haya prometido en serio que habrá de cumplirla». Solo incurría en la censura el solicitado que no cumpliese el deber de denunciar y no aquellos conocedores de cualquier modo de la solicitación y que no realizaran la denuncia. Estos últimos estaban obligados a denunciar, si conocían los hechos de personas dignas de fe, pero solo sub gravi, no bajo la pena de la censura: en el siguiente apartado estudiaremos con más detalle esta obligación.

En el penitente solicitado recaía la obligación de denunciar: los autores alegaban como causas que excusaban de esta obligación el peligro de grave daño en la vida, fama, bienes del denunciante o de sus familiares, supuesto que

22 Bajo la denominación de crimen pessimum se incluían algunos delitos contra el sexto mandamiento cometidos por un sacerdote, en las circunstancias que describía el c. $2359 \$ 2$ CIC 17 (entre otros delitos): la bestialidad, la homosexualidad y los abusos a menores de 16 años (pedofilia). Estos delitos pasaban a ser competencia del Santo Oficio: cfr. U. LóPEZ, De crimine pessimo inter alios, Periódica 27 (1938) 32-35; A. Yanguas, De crimine pessimo et de competentia S. Officii relate ad illud, Revista Española de Derecho Canónico 1 (1946) 427-439; SAGRADA CONGREgaCión DeL SANTO Oficio, Instr. Crimen sollicitationis, 16-III-1962, n. 73: http://bit.ly/ 2PKbWWi.

${ }^{23}$ Cuando un sacerdote conocía en la confesión que el penitente fue solicitado, tenía la obligación de advertirle del grave deber de denunciar ante los Superiores competentes; y en el caso de que se negara sin causa que lo justificase, debía despedirle sin la absolución. 
del silencio no fuera a seguirse un mal público (cfr. c. $1935 \$ 2$ CIC 17). No excusaba el miedo grave a incurrir en la indignación del solicitante, ni las molestias que el penitente pudiera sufrir por hacer la denuncia, ni la buena fe o ignorancia en el momento de la solicitación ${ }^{24}$.

Al regular el delito de solicitación en el c. 1387 CIC 83, la actual normativa suprime esta obligación jurídica de denunciar que imponían los cc. 904 y $2368 \$ 2$ del CIC 17. Tal obligación penal ya no existe en el vigente ordenamiento: como indicaba el coetus de revisión de la parte penal del CIC 17, esta cuestión se debe tratar según los principios de la teología moral ${ }^{25}$. Conviene tener en cuenta que por ley natural el penitente puede estar obligado moralmente a denunciar; así lo vuelve a recordar la doctrina que comenta este canon: por ejemplo, en el caso de reiteradas solicitaciones por parte del sacerdote, por exigencia del bien de las almas o escándalo público, etc. ${ }^{26} \mathrm{Y}$ si un sacerdote tiene conocimiento en la confesión de que el penitente fue solicitado debe advertirle de la posible obligación de poner el hecho en conocimiento de los Superiores competentes, sobre todo si hay escándalo y grave peligro para las almas: dentro de esta advertencia, y en el supuesto que el penitente manifieste que no notificará nada a la autoridad eclesiástica, no parece que el confesor pueda llegar a negarle la absolución sacramental ${ }^{27}$.

${ }^{24}$ Cfr. F. M. CAPPELlo, Tractatus canonico-moralis. De sacramentis, Taurini-Romae 1953, vol. II, n. 447, $6^{\circ}-7^{\circ}$.

25 «Aliquis Consultor quaerit rationes ob quas abolitio can. 904 CIC facta est, quia praecise in illo canone agebatur de obligatione ex parte paenitentis sacerdotem reum denuntiandi. In relatione Sessionis VIII, habite dd. 8-13 novembris 1971, haec quae sequuntur de re notantur: Ad can. 904 CIC. Unus Consultor aestimat quod retineri non debet: confessarius non potest obligare ad denuntiandum, sed monere, consulere tantum. Alter Consultor loquitur de difficultate obtinendi denuntiationem. Relator respondet quod non sunt miscenda quae ad forum conscientiae et quae ad forum sociale pertinent. Concordat omnes ut supprimatur canon, quia est quaestio theologiae moralis. Iuxta alicuius Consultoris sententiam obligatio ex parte paenitentis accusandi sacerdotem reum de sollicitatione non habetur et quaerit num necessarium sit ut haec obligatio adiungatur. Consultor, a quo quaestio mota est, anceps quia revera causa, qua requirebatur canon, non cessavit, sed tamen Sacra Paenitentiaria Apostolica nihil hac de re in suis inadversionibus notavit. Unus Consultor tenet necessarium non esse obligationem denuntiationis adiungere, cum ablata sit reservatio peccati falsae denuntiationis de sollicitatione, sed anceps manet. Etiam alii Consultores ancipites sunt, et omnes conveniunt ut res denuo consideretur»: Communicationes 10 (1978) 64-65.

${ }^{26}$ Cfr. A. Calabrese, Diritto penale canonico, Frascati 1988, 254; J. Llobell, I delitti riservati alla Congregazione per la dottrina della fede, en GRUPPO ITALIANO DOCENTI DI DiRITTO CANONICO (a cura di), Le sanzioni nella Chiesa. XXIII Incontro di studio, Abbazia di Maguzzano, 1-5 luglio 1996, Milano 1997, 271; V. DE PAOLIS, De delictis contra sanctitatem sacramenti paenitentiae, Periodica 79 (1990) 209-210.

27 Cfr. V. DE PaOLIS, De delictis..., cit., 209-210. 
A este respecto, ¿qué dice la nueva normativa que comentamos? El mp sobre la protección de menores indica que «todos sean conscientes del deber de denunciar los abusos a las autoridades competentes y de cooperar con ellos en la actividad de prevención y persecución», por lo que pone en primer lugar a la víctima en la señalización de un posible abuso ante el Vicario general o el Supervisor, en esta primera fase de acogida, escucha y acompañamiento y que posteriormente deberá formalizarse por escrito, con el propósito de comunicarlo al Promotor de justicia del Tribunal del Estado de la Ciudad del Vaticano (cfr. Vademécum, F, n. 1). Para ello, el Vicario o el Supervisor alentará al autor de la información a que presente la denuncia directamente al Promotor de justicia en el Tribunal de la Ciudad del Vaticano (cfr. Vademécum, F, n. 4). Cuando las noticias de un crimen no son manifiestamente infundadas, el Vicario general también puede informar al Promotor de justicia (cfr. Vademécum, F, n. 6).

Sin embargo, no existe una indicación explícita de la obligación de denunciar. Encontramos algo de modo indirecto en el Vademécum, donde se recoge la labor del Vicario general o el Supervisor: la expresión que utiliza es "se alentará" a que denuncie. Como respuesta a esta invitación, puede suceder que la persona lesionada o sus representantes legales se opongan de forma escrita y justificada a que se investigue el suceso o que se nieguen a formalizar la denuncia por escrito: en estos casos, el Vicario general no la transmitirá al Promotor de justicia a menos que, después de haber oído al Supervisor para la protección de los menores, considere que dicha señalización sea necesaria para proteger a la persona lesionada o a otros menores en peligro (cfr. Vademécum, F, n. 7).

Se puede decir, concluyendo, que existe una obligación moral de denunciar, si bien se admiten motivos para no hacerlo, como ya indicaba la doctrina para el caso de solicitación en confesión.

\subsection{Obligación de conservar o revelar un secreto por parte de terceras personas}

No siempre es obligatorio manifestar con la palabra el propio pensamiento: tanto la moral como el derecho consideran lícito y obligatorio, en muchos casos, el silencio y el secreto ${ }^{28}$. Normalmente, se distingue entre el secreto prometido y el secreto natural. El secreto prometido es el que debe guar-

${ }^{28}$ Para un desarrollo de estas materias pueden verse las voces y la bibliografía que se adjunta en R. Palomino, «Secreto», DGDC, VII, 180-183; D. DE CiTO, «Sigilo sacramental», DGDC, VII, 307-310. 
darse en virtud de una promesa. Esa promesa puede ser expresa, en cuyo caso se habla de secreto comisorio, o bien puede ser tácita o implícita al tipo de relación social o jurídica que se mantiene, en cuyo caso el secreto así guardado se denomina profesional. Lo que diferencia esencialmente el secreto profesional (o confiado) del comisorio es el cuasicontrato que en aquel se produce: el depositario del secreto no lo transmitió sino bajo la garantía -normalmente implícita- del sigilo asegurado. Gran parte de las elaboraciones jurídicas acerca del secreto se han realizado a partir del secreto profesional. El secreto natural es el constituido por el conjunto de hechos que deben permanecer ocultos por su misma naturaleza y cuya revelación acarrearía un perjuicio individual o colectivo, comprometiendo los diferentes bienes a los que el hombre y la sociedad tienen derecho. La obligación del secreto tiene en este caso a la justicia como fundamento.

El secreto también acompaña a los sacramentos en la medida en que la confidencialidad resulta necesaria u oportuna. Se hace especialmente presente en el sacramento de la penitencia, con el sigilo sacramental (cfr. c. $983 \$ 1$ ), extendiendo el deber de secreto al ámbito del denominado "secreto penitencial”, que abarca incluso la recepción en calidad de mediador y la recepción accidental (cfr. c. $983 \$ 2$ ). La obligación del sigilo recae tan solo sobre el confesor por la confesión sacramental hecha con el objeto de obtener la absolución, aunque esta pueda eventualmente ser denegada ${ }^{29}$.

Por otra parte, el Derecho procesal canónico reconoce el derecho al secreto en favor de determinados testigos: se impone un deber de callar (o simplemente se exime de la declaración) a magistrados, médicos, abogados y notarios (cfr. c. $1548 \$ 2$ ), por su particular posición entre el sujeto y el conocimiento del secreto, en la que existe una conexión de exigencia y no solo de mera ocasionalidad. También se extiende este secreto procesal a los clérigos en lo que se les ha confiado por razón del ministerio (cfr. c. $1548 \$ 2,1^{\circ}$ y DC art. $194 \$ 2,1^{\circ}$ ); no se refiere al sigilo sacramental (se establece la incapacitación, c. $1550 \$ 2,2^{\text {o } 30}$ y DC art. $196 \$ 2,2^{\circ}$ ), sino al secreto ministe-

29 En cambio, no hay obligación de sigilo en el caso de una confesión claramente simulada o cuando la fingida confesión se haya hecho con el fin de extorsionar o amenazar al confesor o a terceros.

${ }^{30} \mathrm{El}$ c. $1550 \$ 2,2^{\circ}$ establece que se consideran incapaces de ser testigos «los sacerdotes, respecto a todo lo que conocen por confesión sacramental, aunque el penitente pida que lo manifiesten; más aún, lo que de cualquier modo haya oído alguien con motivo de confesión no puede ser aceptado ni siquiera como indicio de la verdad». 
rial que se deriva del "estado", de la dirección espiritual, etc. Por último, el Código de Derecho Canónico protege igualmente el secreto familiar, estableciendo una exención para quienes «temen que de su testimonio les sobrevendrá infamia, vejaciones peligrosas u otros males graves para sí mismos, para el cónyuge, o para consanguíneos o afines próximos» (c. $1548 \$ 2,2^{\circ}$ y DC art. $\left.194 \$ 2,3^{\circ}\right)$.

¿Qué nos dice la nueva regulación? Como indica el mp sobre la protección de menores, «todos sean conscientes del deber de denunciar los abusos a las autoridades competentes y de cooperar con ellos en las actividades de prevención y persecución»; y la Ley CCXVII, art. 3, n. 3, insiste que «cualquier otra persona, incluso totalmente ajena a los hechos, que tenga conocimiento del comportamiento contra un menor puede presentar una denuncia» ${ }^{31}$.

Nos podemos preguntar cómo se ha de entender esa obligación moral de denunciar y a quien le incumbe. Como señalamos anteriormente sobre la solicitación en confesión, la doctrina opinaba que: a) en el CIC 17 el solicitado estaba jurídicamente obligado a denunciar; pero una tercera persona solo estaba obligado moralmente sub gravi si conocía los hechos de personas dignas de $\mathrm{fe}^{32}$; b) en el CIC 83, para todos solo existe una obligación moral de denunciar ${ }^{33}$.

En su aspecto moral, al margen del peculiar régimen del sigilo sacramental y del secreto sacramental protegidos ambos por los cc. 983 y 1388 (cfr. mp, Ley y Vademécum ${ }^{34}$ ), el deber de secreto cede o desaparece en atención

${ }^{31}$ En el Vademécum, F, n. 3 hay una disposición similar: «los agentes de pastoral, los colaboradores y los voluntarios que tienen noticias de que un menor es víctima de explotación, abuso sexual o maltrato, informarán directamente al Vicario general o a través del Supervisor para la protección de los menores».

32 Cappello sostuvo que la obligación de denunciar recae sobre quien conoce el delito de solicitación bajo secreto natural o promisorio, también bajo juramento. Ciertamente no quien sabe del delito bajo sigilo sacramental. Respecto a las personas que conocen este delito bajo secreto de consejo, si se trata de secreto simple, deben denunciarlo; si se trata de secreto de oficio o profesional, no urge per se la obligación, pero per accidens puede que sí urja, si la omisión de la denuncia acarreaba un daño gravísimo al bien público, cfr. F. M. CAPPELLO, Tractatus canonico-moralis..., cit., II, n. 448.

33 Cfr. A. Calabrese, Diritto penale..., cit., 254; J. Llobell, I delitti riservati..., cit., 271; «Haec autem denuntiatio esse potest sive quia christifidelis ius habet semper denuntiandi apud auctoritatem competentem ministros qui non adimplent ad normas legis, sive divinae sive humanae, proprium officium, sive quia esse potest obligatio iuris naturalis denuntiandi apud auctoritatem facta quae scandalum praebent et periculum constituunt bono animarum. Sed iudicium proferre de hac possibili obligatione non est facile»: V. DE PAOLIS, De delictis..., cit., 209-210.

${ }^{34}$ Cfr. mp sobre la protección de menores, n. 2; Ley CCXVII, art. 3, n. 2 y Vademécum, F, n. 3. 
a un interés superior, un grave daño irreparable para sí mismo, para un tercero o para el bien común, como indica el CEC n. $2491^{35}$.

Para contestarlo nos vamos a centrar en dos situaciones, ya sea que por el trabajo desarrollado conozca directamente de la víctima el suceso, ya sea que lo conozca por cualquier otra persona o medio ${ }^{36}$ :

a) Que directamente la víctima lo revele a un tercero (sacerdote, abogado, psicólogo, educadores, familiar cercano) con ocasión de solicitar un consejo o ayuda estrictamente profesional ${ }^{37}$. Nos parece que a estas personas se les debe respetar su secreto profesional y no deberían denunciar estos delitos, a no ser que urja un daño gravísimo al bien público. Estas personas, además de escucharle, acompañarle, etc., deberían valorar las circunstancias que conocen (gravedad de los hechos, reiteración, etc.) y la personalidad de la víctima y, si lo ve oportuno:

- si todavía es menor de edad, informar a sus padres o tutores de la información que ha recibido, con el fin de que sean ellos quienes afronten la situación;

- si es mayor de edad, aconsejar o no a la víctima que directamente informe y denuncie el caso ante la autoridad competente eclesiástica. Puede suceder que la víctima no se vea capaz y prefiera que sea el sacerdote, abogado o familiar quien realice la denuncia, para lo que no habría inconveniente, habida cuenta que en su momento las leyes procesales sobre la solicitación en confesión preveían esta posibilidad ${ }^{38}$.

35 «Los secretos profesionales -que obligan, por ejemplo, a políticos, militares, médicos, juristaso las confidencias hechas bajo secreto deben ser guardados, salvo los casos excepcionales en los que el no revelarlos podría causar al que los ha confiado, al que los ha recibido o a un tercero daños muy graves y evitables únicamente mediante la divulgación de la verdad. Las informaciones privadas perjudiciales al prójimo, aunque no hayan sido confiadas bajo secreto, no deben ser divulgadas sin una razón grave y proporcionada»: CEC, n. 2491.

36 También hay que tener en consideración el tratamiento legal de la confidencialidad de los trabajos que se relacionan con los menores (educación, medicina, etc.) establecidos por los Estados, así como las buenas prácticas profesionales al uso en el ejercicio de esas actividades.

37 Además, si estuvieran en las circunstancias de que el derecho procesal les eximiese de la declaración como testigos (cfr. cc. $1548 \$ 2,1^{\circ} ; 1550 \$ 2,2^{\circ}$ y $1548 \$ 2,2^{\circ}$ ) constituiría un argumento más para no realizar la denuncia.

38 «La responsabilidad de hacer la denuncia es personal, y normalmente la descarga por parte de la persona que ha sido solicitada. Pero si le impiden dificultades muy graves para hacerlo él mismo, entonces debe acercarse al Ordinario o a la Sagrada Congregación del Santo Oficio o a la Penitenciaría Sagrada, ya sea por carta o a través de otra persona que haya elegido, describiendo todas las circunstancias (Instrucción del Santo Oficio, 20 de febrero de 1867, n. 7)»: Instr. Crimen sollicitationis, n. 19. 
b) Que conozca el delito indirectamente: por otras personas que saben del abuso, por informaciones en medios de comunicación, etc. En estas situaciones habría que valorar la certeza de los hechos (personas dignas de crédito y si son testigos o lo saben de segunda mano, rumores, etc.), la gravedad, posibilidad de reiteración, etc., además del motivo por el que una persona conoce dichos hechos, así como la defensa del bien común (cfr. CEC n. 2491). Si se tratara de un sacerdote en el ejercicio del acompañamiento espiritual (o en ejercicio de la abogacía o medicina), opinamos que no sería oportuno que denuncie directamente, y que lo mejor sería, en su caso, recomendar a la persona informante que lo haga. Sugerimos esta solución por dos motivos: estas personas (sacerdote, abogado, etc.) serían testigos muy alejados de las circunstancias de los hechos; y por la importancia de respetar al máximo la confidencialidad de estas personas en el ejercicio de su profesión.

\section{MEDIDAS A FAVOR DE LA PROTECCIÓN Y ACOMPAÑAMIENTO DEL MENOR}

Ya hemos señalado las medidas procesales encaminadas a una mayor protección del menor. En este apartado veremos cómo la Iglesia, a través de esta normativa, desea promover una serie de acciones desde una doble perspectiva, y en ambos casos, marcadas por el principio de acompañamiento y privacidad (escuchar y mantener informada a la víctima de los pasos y decisiones que se han tomado): búsqueda de la curación psicológica y espiritual de la víctima, así como asesoramiento legal en todo el proceso jurídico que se abre con su declaración ante la autoridad eclesiástica (denuncia y posterior juicio).

\subsection{Medidas legales en la protección de los menores}

Como principio general, en el mp sobre la protección de menores se ofrece a la persona lesionada asistencia así como información útil de carácter legal. Este asesoramiento se realiza a través del Servicio de acompañamiento (cfr. mp sobre la protección de menores y Ley CCXVII, art. 9). Por otra parte, en los nn. 1 y 11 del apartado $\mathrm{F}$ del Vademécum se ejemplifican actuaciones legales que hay que tener en cuenta en estos supuestos. Sin embargo, es en la Ley CCXVII, art. 4, donde se especifican las medidas generales de protección de la persona lesionada: a) recibir información sobre los derechos y 
servicios a su disposición y, si lo solicita, sobre los resultados de las fases individuales del procedimiento; b) estar informado de la adopción y terminación de medidas cautelares, provisionales o definitivas, adoptadas contra el acusado; c) directamente o a través del abogado, proporcionar pruebas, solicitar la realización de la investigación y solicitar ser escuchado; d) derecho a la protección de su imagen y privacidad, así como a la privacidad de sus datos personales; e) solicitar que se tomen las medidas apropiadas para evitar el contacto directo con el acusado. $\mathrm{Y}$ en el art. 9, al concretar las competencias del Servicio de acompañamiento, además de hacer referencia a las anteriores medidas, se menciona que se debe ilustrar a la persona lesionada de sus derechos y la forma de hacerlos cumplir, llegando a facilitar la denuncia de la persona ofendida ante la autoridad judicial.

Querríamos hacer un pequeño excursus a propósito de lo aquí indicado. En primer lugar, este Servicio -y la persona que lo dirige- deben tener una actitud de respeto a la posible víctima, pero en sus actuaciones no debe existir una predisposición en contra del acusado. Nos parece interesante destacar este aspecto y no suponerlo como algo obvio. Como hemos visto más arriba, en el mp sobre la protección de menores se reafirman una serie de derechos del acusado (posibilidad de asesoramiento legal, privacidad hasta condena en firme de sus datos, etc.), así como otras garantías en el Vademécum, F, n. 12: todo ello debe ser tenido en cuenta por este Servicio, con el fin de que no se produzca un riesgo de indefensión del acusado (piénsese en el tratamiento a veces morboso de estos asuntos en los medios de comunicación, y que, a veces, existe un peligro real de condena pública sin haber sido juzgado).

\subsection{Actuaciones sociales en favor del menor: acompañamiento y escucha, y asistencia espiritual, médica y social de las víctimas}

En el mp sobre la protección de menores se reconoce de manera amplia a quienes afirman haber sido víctimas de explotación, abuso sexual, así como a sus familias, el derecho a ser recibido, escuchado y acompañado. En estos casos, se ofrece atención pastoral adecuada, así como apoyo espiritual, médico y psicológico, protegiendo su privacidad y confidencialidad. En estos ámbitos, se encomienda al Vicario general, directamente o a través del Supervisor para la protección de menores, estas actuaciones de acompañamiento y asesoramiento (cfr. Vademécum, F, nn. 1, 2 y 11), que se realizarán a través del Servicio de acompañamiento (cfr. Ley CCXVIIX, art. 9). 
Respecto al asesoramiento legal, se define de forma amplia, para facilitar al máximo todas las actuaciones que puedan ponerse en marcha en este campo.

Si se nos permite la analogía, toda esta actividad previa se asemeja a la nueva institución creada para el sistema matrimonial: la "Investigación prejudicial o pastoral" del mp Mitis Iudex ${ }^{39}$. Un acompañamiento global en lo espiritual, pastoral, legal y médico, pero que no se queda simplemente en la fase previa a la posible apertura de un procedimiento penal, o en el acompañamiento y asesoramiento que se podrá proporcionar durante todo el proceso penal, sino que va más allá, pudiendo pensarse que la labor de la Iglesia no termina aquí: debe estar siempre con las víctimas, apoyando y sosteniendo a sus hijos en lo pastoral y espiritual, incluso en los aspectos médicos y psicológicos.

Como resumen de estos dos apartados podemos resaltar el deseo que la Iglesia tiene de reorientar toda su actuación realizada hasta ahora: poner el centro de su preocupación en las personas que han sufrido estos abusos, y, para ello, se toman medidas y actuaciones de acogida, acompañamiento y cuidado, todo ello con una finalidad sanadora y pastoral. Estas orientaciones pueden servir de guía a las Conferencias episcopales en sus Vademécums para los obispos de su región.

Por otra parte, queremos señalar que las personas que trabajan en este asesoramiento legal y el Supervisor (en cuanto a su función de relacionarse directamente con la víctima y su familia durante todo el procedimiento), estarían incapacitadas para ser posteriormente instructores de la investigación previa penal y, como es lógico, jueces del posible proceso penal. Lo hacemos notar porque nos parece que afectaría a su imparcialidad en esas funciones procedimentales, al poder tener una precalificación penal de lo ocurrido ${ }^{40}$.

\section{SERVICIO RESPONSABLE EN LAS ACCIONES QUE SE HAN DE IMPLEMENTAR} PARA LA PROTECCIÓN DE MENORES

Con estas normas se crea un nuevo servicio en el Estado de la Ciudad del Vaticano dependiente del Governatorato, a través de la oficina de Dirección de Salud e Higiene. En esta oficina habrá un Servicio de acompañamiento para las víctimas de abusos coordinado por un Responsable (cfr. mp sobre la pro-

${ }^{39}$ Cfr. G. NúÑEZ, La fase preliminar del nuevo proceso de nulidad, Ius Canonicum 57 (2017) 9-44.

${ }^{40} \mathrm{La}$ incompatibilidad jurídica la tiene solo el Investigador penal, que luego no puede ser juez de la causa: cfr. c. $1727 \$ 3 \mathrm{CIC} 83$. 
tección de menores nn. 3-4, Ley CCXVII, art. 8). Por otra parte, se crea otro oficio al que se denomina Supervisor, que es nombrado por el Vicario general de la Ciudad del Vaticano ${ }^{41}$, y cuyas competencias son las de ayudar al Vicario general en verificar el cumplimiento de las indicaciones de la nueva normativa (cfr. Vademécum, B).

\subsection{El servicio de acompañamiento para las víctimas de abuso. El Supervisor}

Como hemos indicado, la normativa contempla un servicio específico y cualificado, coordinado por un responsable. Este servicio se va a encargar de la puesta en marcha y verificación de las actuaciones de acompañamiento a las víctimas, así como todo lo referente a la formación del personal que trabaja en el Estado de la Ciudad del Vaticano y en la Curia Vaticana.

En el art. 9 de la Ley CCXVII se delinean las funciones de este servicio: a) ofrece un servicio de escucha; b) garantiza la asistencia médica y social a las personas lesionadas y a sus familias, incluida la asistencia terapéutica y psicológica de emergencia; c) ilustra a la persona lesionada de sus derechos y la forma de hacerlos cumplir; d) facilita la denuncia de la persona ofendida ante la autoridad judicial; e) tiene en cuenta la opinión y las necesidades de la parte perjudicada, protegiendo su imagen y privacidad, así como la confidencialidad de los datos personales; f) adopta pautas de cómo tratar a los menores que utilizan estos servicios.

En el Vademécum, B, se describen las funciones del Supervisor: coordinación de las actividades de prevención y capacitación de los agentes de pastoral y se encargará especialmente de acoger y acompañar a las personas que afirman haber sido víctimas de explotación, abuso sexual o maltrato, así como a sus familias. Para ello, continúa el Vademécum, el Supervisor estará ayudado por el Servicio de Acompañamiento, administrado por la Dirección de Salud e Higiene del Governatorato, y de la Oficina de Trabajo de la Sede Apostólica.

Dada la amplitud con la que se concibe este Servicio, entre su personal deberán contarse personas expertas en psicología, derecho, medicina... así como algún sacerdote para ejercer la orientación espiritual.

${ }^{41}$ «El Vicariato de la Ciudad del Vaticano, encargado de la pastoral de los fieles que residen en el Estado de la Ciudad del Vaticano, así como en las Villas Pontificias de Castelgandolfo, participa plenamente en esta misión, firmemente enraizado en la convicción de que cada persona tiene un valor único creados a la imagen y la semejanza de Dios»: Vademécum, Introducción. 
En el ámbito diocesano sería muy oportuno crear también este Servicio y nombrar a un Supervisor que colabore con el Obispo (principal responsable de estas materias) en su labor de acogida, ayuda, y en su caso de orientación legal de las víctimas que acudan a él.

\subsection{Competencias: selección, contratación, idoneidad y formación del personal}

Además de lo indicado hasta ahora, en el conjunto de la normativa se especifican otra serie de competencias con incidencia clara en aspectos jurídicos.

El Servicio de acompañamiento participa en el proceso de contratación y selección de personal, voluntario o no, que trabaja en el Vaticano, con el fin de comprobar la idoneidad del candidato para relacionarse con menores y personas vulnerables (cfr. mp sobre la protección de menores n. 5; Ley CCXVII art. 11). Para ello, se elaborarán pautas y procedimientos para determinar esta idoneidad. Y en el Vademécum, C, se especifica, al hablar de los agentes de pastoral, que debe realizarse una investigación adecuada en la que se verifique la ausencia de cargos judiciales en los interesados.

Nos parece que en estos procesos de selección y contratación se deben incluir aquellos protocolos que aseguren un mínimo de idoneidad. Aunque no se especifica más, pensamos que se podrían aprobar algunas de estas medidas: realizar tests psicológicos de personalidad desde una perspectiva antropológica cristiana ${ }^{42}$; necesidad de aportar certificados penales de la autoridad estatal de que no se ha estado incurso en penas por estos delitos; solicitar testimonios de probidad, tradicionales en el Derecho Canónico, como los pareceres del párroco o sacerdotes, etc. (cfr. c. 1572).

En esos procesos también debería estar claro que no se puede contratar, o dar el visto bueno a que participe en tareas pastorales a quien no reuniera los requisitos mínimos. Especialmente se debe ser exigentes en la contratación de personal o la colación de oficios ${ }^{43}$ : estas personas representan en su trabajo a la Iglesia, de una manera u otra. Sin embargo, nos parece que resulta más complicado concretar y llevar a la práctica este tipo de exigencias en colabo-

${ }^{42}$ Cfr. W. Vial, Psicología y celibato, Scripta Theologica 50 (2018) 139-166.

${ }^{43}$ Cfr. A. VIANA, La comprobación de la idoneidad para el oficio eclesiástico y el orden sagrado, Ius Ecclesiae 28 (2016) 345-366; ¿ Son idóneos para el oficio eclesiástico los divorciados que contraen nuevo matrimonio civil?, Ius Canonicum 56 (2016) 515-553. 
radores voluntarios pastorales: piénsese en catequistas esporádicos, o voluntarios en actividades culturales puntuales, etc.

Pensando en las diócesis o en las parroquias, se podrían adoptar bastantes de estas medidas siempre que se refieran al personal fijo o a la colación de oficios. Respecto del personal voluntario, los párrocos, o las personas responsables de las actividades, deberán velar para que los que interactúen con menores sean personas de comprobada honestidad.

Respecto a la formación del personal de la Curia, también de los agentes pastorales y voluntarios, debe extenderse a los aspectos jurídicos así como a las buenas prácticas en la atención de las personas. Esta formación se ofrece por la Oficina de Trabajo de la Sede Apostólica, junto con el Servicio de Acompañamiento de la Dirección de Salud e Higiene, a través de programas de capacitación sobre los riesgos en materia de explotación del abuso sexual y maltrato de menores y personas vulnerables, así como de los medios para identificar y prevenir tales delitos y la obligación de informar (cfr. mp sobre la protección de menores n. 4, Ley CCXVII art. 10, Vademécum, C). Estos cursos y programas irán dirigidos no solo a los trabajadores fijos con cargos pastorales o no, sino que también se deben proporcionar a otros colaboradores ocasionales, informándoles de cómo deben actuar en la relación con los menores, así como sobre los comportamientos prohibidos (cfr. Vademécum, C).

El contenido de los cursos debería incluir el conjunto de la normativa (disposiciones procesales, experiencias en la labor pastoral con menores), adaptándolos a las necesidades de las personas a las que vayan dirigidos: cursos de formación permanente a sacerdotes, agentes de pastoral, voluntarios. También se deberá tener en cuenta el trabajo que desarrollan: cargos de la Curia, representación del Vaticano, estrictamente pastorales, o de servicios de vigilancia y control (policía). Aunque el mensaje de fondo es común a todos ellos, se deberán diferenciar en los aspectos que afecte a su tarea.

Programas análogos de formación habrían de establecerse en las diócesis. Sería importante tratar acerca de todo aquello relacionado con la formación permanente de los sacerdotes, y la labor que debe realizar el Supervisor a la hora de comprobar que los locales parroquiales o los lugares donde se desarrollen las actividades estén de acuerdo con las disposiciones previstas (ver infra el apartado donde se comentan las experiencias pastorales). También es imprescindible que se impartan en la formación de los candidatos al sacerdocio en el Seminario. 


\section{Algunas EXPERIENCIAS PARA TENER EN CUENTA}

EN LA LABOR PASTORAL CON MENORES

En este apartado nos vamos a centrar en las medidas que el Vicario general o el Supervisor deben poner en práctica para que efectivamente en las actividades pastorales, así como en los locales o lugares donde se desarrollen, se consiga prevenir cualquier forma de violencia, abuso, negligencia, abandono o explotación de menores.

Antes, sin embargo, queremos referirnos a dos recomendaciones generales que realiza el Vadémecum, mediante las que se pone de manifiesto el espíritu de protección del menor que debe informar todas las actividades pastorales y a la necesidad de mantener una estrecha relación con los padres o tutores legales (responsables de la vida espiritual y corporal de los menores):

a) La prontitud, delicadeza y prudencia con la que deben abordarse cualquier conducta inapropiada o de acoso, informando inmediatamente a los padres o tutores del menor (cfr. Vademécum, D, n. 4).

b) El consentimiento escrito e informado de los padres y tutores ${ }^{44}$, indispensable para que los menores participen en las actividades pastorales, así como para filmar o publicar sus fotos en el desarrollo de esas actividades, para contactar con el menor por teléfono o en las redes sociales. Estas autorizaciones deben conservarse (cfr. Vademécum, E) ${ }^{45}$. Aunque la Iglesia siempre ha tenido presente esta finalidad, ahora desea recordarla y reafirmarla, dándole un mayor énfasis: la Iglesia debe caminar de la mano junto a los padres o tutores del menor, yendo en la misma dirección, y complementándose en la formación espiritual y humana de los jóvenes. La Iglesia es madre, y como tal, es la primera preocupada que la juventud cristiana camine segura y firme en todos estos aspectos.

Estas consideraciones generales me llevan a realizar una reflexión: ¿no convendría que sean los padres los que en primera persona colaboraran en esas tareas pastorales? Es decir, si ellos son los protagonistas de la formación espiritual y humana de sus hijos, ¿no deberían estar involucrados mucho más de

\footnotetext{
${ }^{44}$ Conviene recordar que en la legislación de muchos países ya existe esta obligación jurídica, que la Iglesia debe cumplir como todas las organizaciones, tanto estatales como privadas, que desarrollan actividades con adolescentes: educativas en centros de enseñanza, clubs deportivos, asociaciones culturales, ongs, etc.

${ }^{45}$ Cfr. Vademécum, E.
} 
lo que están ahora en las labores pastorales? Me parece que es un reto que tiene la Iglesia en su pastoral juvenil. Además, aunaría los esfuerzos en el desarrollo de la pastoral familiar que tan frecuentemente se ha puesto en evidencia en estos últimos tiempos. Cuántas veces la Iglesia ha visto renacer en las familias la fe a través de las catequesis a los niños de primera comunión, o de confirmación, o al implicar a los padres en las actividades (culturales, deportivas, campamentos de verano) de los colegios y de las parroquias, etc. Una experiencia multisecular, tantas veces confirmada: a los padres se llega a través de los hijos, especialmente cuando los hijos son menores de edad.

\subsection{Relaciones interpersonales con el menor}

En este campo, el Vademécum, D, n. 1, recuerda que en las actividades pastorales en las que participen menores se debe dar prioridad a la protección de estos. Con este fin se enumera un elenco de acciones y de informaciones que se han de proporcionar a los padres y tutores sobre las actividades y métodos con los que se llevarán a cabo, y se hace una llamada reiterada a la prudencia por parte de los agentes de pastoral en el trato con los menores, que la experiencia ha demostrado que son necesarias ${ }^{46}$.

De otra parte, además de estas actitudes, se ejemplifican otra serie de actuaciones que están estrictamente prohibidas a los agentes de pastoral, entre las que se incluyen reprimendas físicas o psicológicas, establecer una relación preferencial o discriminatoria con un menor, intercambiar fotografías personales, etc. ${ }^{47}$

46 Vademécum, D: «Actividades pastorales. 1. En las actividades pastorales que involucren a menores, se debe dar prioridad a la protección de estos. Por lo tanto, en el curso de sus actividades, los agentes de pastoral deben: - usar la prudencia y el respeto en relación con los menores; - proporcionarles modelos de referencia positivos; - estar siempre visibles ante los demás cuando están en presencia de menores; - informar a los responsables de cualquier comportamiento potencialmente peligroso; - respetar la esfera de confidencialidad del menor; - informar a los padres o tutores de las actividades propuestas y los métodos organizativos relacionados; - usar la debida prudencia en la comunicación con los menores, también por teléfono y en las redes sociales».

47 Vademécum, D: «Actividades pastorales. 2. Está estrictamente prohibido para los agentes de pastoral: - infligir castigos corporales de cualquier tipo; - establecer una relación preferencial con un menor de edad; - dejar a un menor en una situación potencialmente peligrosa debido a su seguridad mental o física; - dirigirse a un menor de manera ofensiva o asumir comportamientos improcedentes o sexualmente alusivos; - discriminar a un menor o un grupo de menores; - pedir a un menor que guarde un secreto; - dar regalos a un menor discriminando al resto del grupo; - fotografiar o filmar a un menor sin el consentimiento por escrito de sus padres o tutores; - publicar o difundir, a través de la red o la red social, imágenes que reconozcan a un menor de una manera reconocible sin el consentimiento de los padres o tutores». 
Todas estas medidas son de aplicación directa en las actividades pastorales diocesanas y se tendrían que tener muy en cuenta, además de ser unos de los contenidos obligatorios en los cursos de formación que se impartan para sacerdotes y agentes de pastoral.

\subsection{Estructuras y lugares para compartir en las actividades pastorales}

El Vademécum, D, n. 3 señala que «las actividades pastorales se llevan a cabo en instalaciones adecuadas para la edad y la etapa de desarrollo de los menores. En la medida de lo posible, los agentes de pastoral deben tener especial cuidado para asegurarse de que los menores no entren ni permanezcan en lugares ocultos a la vista o fuera de control». Esta indicación nos parece que tendrá gran relevancia en la labor del Supervisor, como ya hemos indicado supra, en toda su labor de control, asistencia y colaboración en el Estado de la Ciudad del Vaticano. No se concreta más esta indicación: indudablemente el Supervisor con el Servicio de acompañamiento deberán realizar una labor de verificación, pero antes, tendrán que elaborar criterios y pautas de actuación para estos casos.

En ámbito diocesano, el responsable de estas labores deberá estar en estrecha relación con los párrocos, ofreciéndoles soluciones en lo referente al lugar donde se desarrollen las actividades pastorales. En líneas generales estamos pensando en el aspecto arquitectónico de los locales parroquiales, donde se imparten las catequesis y otras actividades culturales. Muchos de ellos pertenecen a edificios que se construyeron hace decenios y que no reúnen todas las exigencias que estas palabras, en su dicción lacónica, encierran en realidad. En esto, las leyes estatales pueden dar pistas de las características que deben reunir estos locales, al señalar medidas de protección de menores en los edificios de centros de enseñanza, clubs deportivos, etc. A modo de ejemplo, se deben tener en cuenta que las habitaciones deben verse desde fuera (lo que implica que tengan puertas con cristal), las salas de ordenadores deben estar en lugar público, verificar la comunicación e independencia de la parroquia con la casa parroquial, etc.

Por otra parte, también deben de estudiarse aquellas estructuras, locales y lugares donde se desarrollan actividades de recreo o al aire libre con la juventud, ya sea de manera esporádica y puntual (como campamentos de verano, excursiones, etc.), así como las que tengan estructuras arquitectónicas fijas. En estas actividades se deben revisar desde cómo se realizan los transportes y via- 
jes con los menores, cómo están los servicios comunes en los lugares de descanso, la separación física de los dormitorios de las personas mayores que atiendan las actividades (sacerdote, religioso, voluntarios) y los menores, tipos de actividades en los que no pueda darse el contacto físico entre mayores y menores, etc. En estos supuestos, el Supervisor debería dar normas claras y específicas de comportamiento, sin dejar nada a la improvisación. Como hemos indicado al inicio de este apartado, especialmente en el desarrollo de estas actividades será muy conveniente que los padres participen y colaboren.

Para terminar, un último apunte estrictamente canónico que, en el supuesto que no se observe, podría estar en el origen de situaciones de abusos a menores. Me refiero al lugar y sede donde se imparte el sacramento de la Penitencia y se realiza el acompañamiento espiritual que se imparte en el mismo ${ }^{48}$, es decir, el lugar y la sede para oír confesiones: a) el lugar propio, que habrá de ser un lugar sagrado (cfr. c. 1205), normalmente en una iglesia u oratorio, al ser los lugares destinados al culto divino en general y a la administración de los sacramentos (cfr. c. $964 \$ 1$ ); b) la sede para las confesiones, que debe tener una determinada ubicación dentro de dichos edificios (cfr. c. 964 \$2).

En relación a la sede, el Código indica que «la Conferencia Episcopal dé normas, asegurando en todo caso que existan siempre en lugar patente confesionarios provistos de rejilla entre el penitente y el confesor que puedan utilizar libremente los fieles que así lo deseen» (c. $964 \$ 2)$. Aunque en la actualidad no es la única sede posible, el confesonario debe existir obligatoriamente siempre: las Conferencias Episcopales que han dictado normas al respecto se mueven entre mantener el confesionario con rejilla fija como único sitio previsto, a ofrecer a los penitentes también otras sedes alternativas a la tradicional, precisando bien las características que deben tener o que sea la autoridad competente quien las fije ${ }^{49}$.

${ }^{48}$ Para un desarrollo de estas cuestiones pueden verse las voces y la bibliografía que se adjunta de B. F. PIghin, «Sede para las confesiones», DGDC, VII, 217-220; e IDEM, «Confesionario», DGDC, II, 508-511.

49 La Conferencia Episcopal Española en su II Decreto General ha establecido en su art. 7 que «de acuerdo con lo establecido en el c. $964 \$ 2$, en las iglesias y oratorios existirá siempre en lugar patente el confesionario tradicional, que puedan utilizar libremente los fieles que así lo deseen. Existirá, además, en la medida en que, por razones de espacio, pueda hacerse así, la sede alternativa prevista en el canon, para cuantos fieles expresamente la pidan y que ha de estar reservada en exclusiva para este ministerio. En cuanto a su forma concreta, se tendrán en cuenta las condiciones de cada lugar y las directrices diocesanas sobre arte sacro y liturgia, garantizando, en todo caso, tanto la facilidad y la reserva del diálogo entre el penitente y el confesor como el carácter religioso y sacramental del acto»: BOCEE 6 (1985) 62. 
Si pensamos en las opciones que tiene el penitente o el ministro respecto a la elección de la sede de la confesión manifestada en el c. $964 \$ 2$, hay que tener en cuenta una interpretación auténtica del canon. De producirse un conflicto de intereses entre la petición del penitente de confesarse en un determinado sitio y la postura del sacerdote, la decisión última, si es favorable al uso del confesonario, compete al confesor y no cabe oponerse a ella ${ }^{50}$. Esta solución se justifica porque el sacerdote tiene derecho a obrar con prudencia y la obligación de tutelar la santidad del sacramento, que puede plantearse respecto a penitentes de uno u otro sexo. Así, por ejemplo, en los casos en los que existiese el peligro de una intromisión del penitente en la vida personal del sacerdote o hubiese riesgo de que se diera una relación interpersonal problemática entre ambos, o comportamientos moralmente sospechosos por parte del segundo o incluso la posibilidad de equívocos por parte de terceros.

Una vez recordada la legislación, convendrá comprobar que efectivamente se realiza así en ámbito diocesano. El Obispo tiene una responsabilidad especial en que se cumpla ${ }^{51}$. En esta labor debería estar ayudado por otra persona, con las funciones del Supervisor que hemos expuesto: especialmente explicando a los sacerdotes todos estos criterios y experiencias. Por otra parte, y donde existan las sedes alternativas al confesonario, se deberán verificar que reúnen las condiciones de ambiente adecuado, evitar malentendidos, etc., y quizá habría que replantearse si será oportuno utilizar estas sedes alternativas en la confesión o acompañamiento espiritual de los menores de edad.

\section{Consideraciones Finales}

Hemos destacado algunos aspectos que nos han parecido relevantes de la nueva normativa vigente en el Estado de la Ciudad del Vaticano. También hemos indicado a lo largo de estas líneas algunos aspectos que convendría poner en marcha en el ámbito diocesano; resumidamente son:

a) Cuidar el aspecto interpersonal en las relaciones con las víctimas y sus familias, acogiéndolas, acompañándolas e informándoles de aquello que les concierne: apoyo psicológico, jurídico, etc.

\footnotetext{
${ }^{50}$ Concretamente, permite que, por justa causa y fuera de los casos de necesidad, el ministro «pueda legítimamente decidir que la confesión sacramental sea recibida en un confesonario provisto de rejilla fija, incluso aunque el penitente solicite otra cosa»: PONTIFICIO CONSEJO PARA LA INTERPRETACIÓN DE LOS TEXTOS LEGISLATIVOS, c. 964 \$2, 7-VII-1998, AAS 90 (1998) 711.

${ }^{51}$ Cfr. cc. $935 \$ 1 ; 837 \$ 1 ; 838 \$ \$ 1$ y $4 ; 841$.
} 
b) Selección de personal y criterios de idoneidad para ocupar oficios y agentes de pastoral que interactúen con menores de edad.

c) Plan de cursos de formación para impartir en los seminarios, a los sacerdotes y a otros agentes pastorales.

d) Criterios pastorales para las actividades con menores tanto en la parroquia, como en otros lugares donde se realicen (campamentos, excursiones, etc.).

e) Verificar que los ambientes donde se llevan a cabo las actividades pastorales son los adecuados, con el fin de evitar cualquier equívoco en estos asuntos: confesionario, locales parroquiales, etc.

f) Oficios y servicios que deberán ayudar al Obispo (primer responsable) en estos temas: un responsable o supervisor que dirija un equipo o servicio con esta finalidad, formado por médicos, abogados, psicólogos, etc.

Como es lógico, todas estas medidas, junto con las que en un futuro se puedan tomar tendrán una eficacia relativa si no van acompañadas de lo principal, la conversión personal, el seguimiento del ejemplo de Cristo que «nos confió el cuidado y la protección de los más pequeños e indefensos: "el que acoge a un niño así en mi nombre, me recibe a mí" (Mt 18,5). Por lo tanto, todos tenemos el deber de acoger generosamente a los menores y las personas vulnerables y crear un ambiente seguro para ellos, tomando en primer lugar sus intereses. Esto requiere una conversión continua y profunda, en la que la santidad personal y el compromiso moral puedan contribuir a promover la credibilidad del anuncio del Evangelio y a renovar la misión educativa de la Iglesia» ${ }^{52}$, como subraya el Papa Francisco.

${ }^{52}$ Mp sobre la protección de los menores, Introducción. 


\section{Bibliografía}

Calabrese, A., Diritto penale canonico, Frascati 1988.

—, sub c. 1390, en Comentario Exegético al Código de Derecho Canónico, IV/1, Pamplona 1996, 565.

Cappello, F. M., Tractatus canonico-moralis. De sacramentis, Taurini-Romae 1953, vol. II.

De Cito, D., «Sigilo sacramental», en J. Otaduy - A. Viana - J. Sedano (eds.), Diccionario General de Derecho Canónico, VII, Cizur Menor 2012, 307310.

FRANCISCO, mp sobre la protección de menores y de las personas vulnerables, 26-III-2019, http://bit.ly/2ZQSwDy.

-, Ley CCXVII sobre la protección de menores y personas vulnerables del Estado de la Ciudad del Vaticano, 26-III-2019, http://bit.ly/2WjZE9g.

-, Vademécum para la protección de los menores y personales vulnerables, 26-III-2019, http://bit.ly/2LjpGZh.

Gudenus, P. E., «Denuncia», en J. Otaduy - A. Viana - J. Sedano (eds.), Diccionario General de Derecho Canónico, III, Cizur Menor 2012, 56-57.

Llobell, J., I delitti riservati alla Congregazione per la dottrina della fede, en GRUPPO ITALIANO DOCENTI DI DiRITTO CANONICO (a cura di), Le sanzioni nella Chiesa. XXIII Incontro di studio, Abbazia di Maguzzano, 1-5 luglio 1996, Milano 1997.

López, U., De crimine pessimo inter alios, Periódica 27 (1938) 32-35.

NúÑEZ, G., La fase preliminar del nuevo proceso de nulidad, Ius Canonicum 57 (2017) 9-44.

Palomino, R., «Secreto», en J. Otaduy - A. Viana - J. Sedano (eds.), Diccionario General de Derecho Canónico, VII, Cizur Menor 2012, 180-183.

PAOLIS, V. DE, De delictis contra sanctitatem sacramenti paenitentiae, Periodica 79 (1990) 209-210.

Pighin, B. F., «Sede para las confesiones», en J. Otaduy - A. Viana - J. SEDANo (eds.), Diccionario General de Derecho Canónico, VII, Cizur Menor 2012, 217-220.

—, «Confesionario», en J. OtAdUY - A. Viana - J. Sedano (eds.), Diccionario General de Derecho Canónico, II, Cizur Menor 2012, 508-511.

Sagrada Congregación del Santo Oficio, Instr. Crimen sollicitationis, 1962, http://bit.ly/2PKbWWi. 
SAnchis, J. M., «Acusación penal», en J. Otaduy - A. Viana - J. Sedano (eds.), Diccionario General de Derecho Canónico, I, Cizur Menor 2012, 191193.

Vial, W., Psicología y celibato, Scripta Theologica 50 (2018) 139-166.

VIANA, A., La comprobación de la idoneidad para el oficio eclesiástico y el orden sagrado, Ius Ecclesiae 28 (2016) 345-366.

-, ¿Son idóneos para el oficio eclesiástico los divorciados que contraen nuevo matrimonio civil?, Ius Canonicum 56 (2016) 515-553.

YAnguas, A., De crimine pessimo et de competentia S. Officii relate ad illud, Revista Española de Derecho Canónico 1 (1946) 427-439. 
CRÓNICAS 
